\title{
Some advantages of three-layer medium-density fibreboard as compared to the traditional single-layer one
}

\author{
Turgay Akbulut(10 and Nadir Ayrilmis * (1)
}

\begin{abstract}
The aim of the study was to develop three-layer medium-density fibreboard (MDF) manufacture by adding the coarse fibres in the middle layer, like three-layer particleboard. The liquid urea-formaldehyde (UF) resin was reduced from 10.5 to $6.5 \mathrm{wt} \%$ in the middle layer of the MDFs. The UF resin content was kept constant at $10 \mathrm{wt} \%$ in the surface layers of all the MDFs. Moreover, the average density of MDFs was decreased from 730 to $650 \mathrm{~kg} / \mathrm{m}^{3}$. The internal bond strength of three-layer MDFs decreased with decreasing UF resin content (10.5 to $8.5 \mathrm{wt} \%$ ) in the middle layer. However, the decreases in the internal bond strength were statistically not significant. The internal bond strength values of the MDFs having density between 730 and $675 \mathrm{~kg} / \mathrm{m}^{3}$ did not show significant differences. The cost savings of the resin were $20 \%$ when the amount of resin was reduced from 10.5 to $8.5 \mathrm{wt} \%$. Three-layer MDFs had lower resin consumption at lower densities over traditional single-layer MDFs produced in the same plant with the same material components without decreasing their technological properties. In conclusion, it can be said that three-layer MDF could be produced at a lower cost than traditional single-layer MDF.
\end{abstract}

Keywords: Three-layer fibreboard, Coarse wood fibres, Technological properties, Density, Resin

\section{Introduction}

Medium-density fibreboard (MDF) is the second most used wood-based composites in furniture production and interior decoration behind three-layer particleboard which has significant advantages such as lower density and lower production cost. In 2017, the largest category by volume in Europe (+EFTA) was particleboard (31.2 million cubic metres), followed by MDF (12.3 million cubic metres) [1]. Particleboard takes up the largest portion of the market of wood-based composites. In the traditional MDF production, surface and middle layers are composed of uniform fine wood fibres. However, the surface layers are made from small particles and the middle layer is made from coarse wood particles in the particleboard production. Due to shortage of wood material worldwide, lightweight design concept, as a promising alternative to conventional panels, has been considered

*Correspondence: ayrilmis74@gmail.com

Department of Wood Mechanics and Technology, Forestry Faculty, Istanbul University-Cerrahpasa, Bahçeköy, 34473 Sarıer, Istanbul, Turkey by the wood-based panel industry. Lightweight boards such as light-fibreboard and light-particleboard have gained a great interest in the furniture industry due to their significant advantages such as light furniture, low production cost, low transportation cost, low wood consumption, and energy savings [2]. In particular, increasing costs of wood material and transportation force manufacturers to decrease the density of panels possessing acceptable technological properties.

The surface quality of MDF is better than that of the particleboard [3]. This is because the fibre size is quite smaller than the surface particles of the particleboards [4]. Particleboard meets the minimum physical and mechanical requirements for panel-type furniture although its middle layer is produced from the coarse particles. To achieve a smooth surface for the MDF, the surface layers should be prepared from fine fibres. However, the fibres in the core layer do not directly affect the surface properties of the MDF. As a result, the core layer of the traditional single-layer MDF can be prepared from 
coarse fibres, which may result in a lower resin consumption as compared to the fibres of surface layers due to decreasing surface area.

Resin is the next expensive raw material after wood material. As compared to the single-layer MDF, threelayer MDF can reduce resin consumption in the middle layer due to decreasing surface area of wood fibres. Urea-formaldehyde (UF) is the most used resin among the thermosetting resins in the production of wood-composite panels for use in dry conditions The significant advantages of UF resin are lower price, easy supply, transparent colour, lower pressing temperature and time, and good mechanical properties in dry conditions.

In the present study, it was aimed to develop threelayer MDF manufacture by adding the coarse fibres in the middle layer. The surface layers of the MDFs were produced from fine fibres and the middle layer was produced from the coarse fibres. The effects of resin content in the middle layer and average panel density on the some technological properties of MDFs were determined.

\section{Materials and methods Wood fibres}

The wood chips of softwood (Pinus sylvestris) and hardwood species (Fagus orientalis Lipsky) were used in the production of MDFs. The round woods having about 20-25-cm diameter were fed into the drum type chipper with three knives using automatic belt feeding system (Pallmann ${ }^{\mathrm{TM}}$ model: PHT $500 \times 1050$, motor force: $500 \mathrm{~kW}$, knife angle: $30^{\circ}$ ). Wood fibres were produced by thermo-mechanical defibrillator (Pallmann ${ }^{\text {TM }}$ model:
PR 48/50) in MDF factory in Turkey called Kastamonu Integrated Wood Company (Kocaeli city, Turkey). Rotational speed of the disc and grinding chamber temperature of the defibrillator (Pallmann ${ }^{\mathrm{TM}}$ model: PR 48/50) were $1500 \mathrm{rpm}$ and $150{ }^{\circ} \mathrm{C}$. The wet fibres were dried in a wood dryer $\left(\right.$ Selnikel $\left.^{\mathrm{TM}}\right)$ to $2-3 \%$ moisture content. The fan speed and air flow rate were $990 \mathrm{rpm}$ and $400.000 \mathrm{~m}^{3} / \mathrm{h}$, respectively. The digester was set to 8 bar, $170{ }^{\circ} \mathrm{C}$, and $4 \mathrm{~min}$. The defibrillator gap distance was kept constant at $0.4 \mathrm{~mm}$ for the production of the surface layer fibres, while it was kept at $0.8 \mathrm{~mm}$ for the production of the middle layer fibres. The length and thickness of the fibres were measured from a hundred fibres. The specimens were randomly selected from the coarse fibres. This procedure was applied for the fine fibres. The fine fibres of pine wood were used in the surface layers, while the coarse fibres of beech wood were used in the core layer. The average length and thickness of the middle layer fibres were found to be $11.5 \mathrm{~mm}$ and $0.73 \mathrm{~mm}$, respectively; while the average length and thickness for the surface layers fibres were $4.30 \mathrm{~mm}$ and $0.51 \mathrm{~mm}$, respectively (Fig. 1).

\section{Resin}

UF resin (E1 grade) with solid content of 50 wt \% acquired from the MDF factory of Kastamonu Integrated Wood Company was used in the production of MDF panels. Liquid ammonium chloride with solid content of $20 \mathrm{wt} \%$ was added to the UF resin as a catalyst.

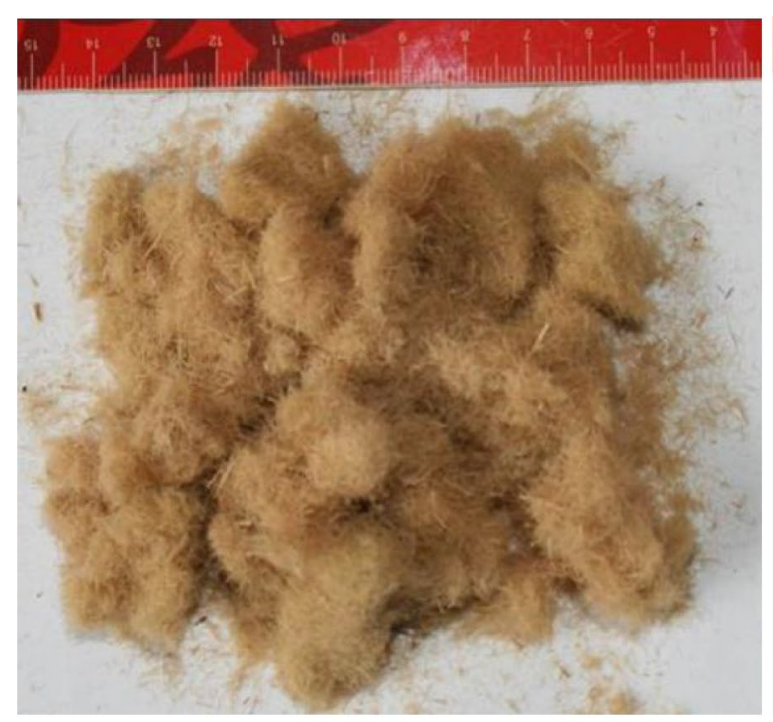

a

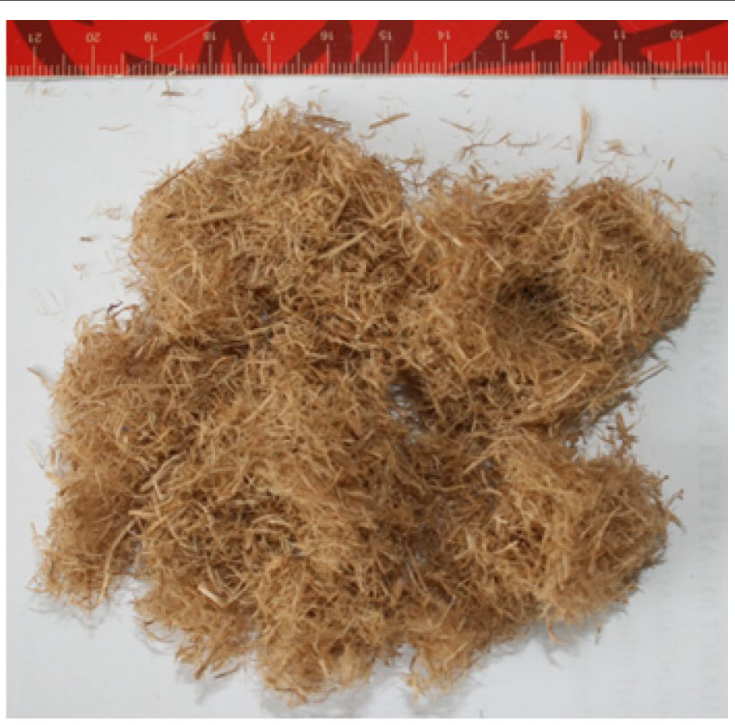

b

Fig. 1 a Fine wood fibres (pine) used in the face layers of MDF. b Coarse wood fibres (beech) used in the core layer of MDF 


\section{Manufacturing of three-layer MDFs}

The surface layers of the MDFs were produced from the fine fibres while the middle layer was produced from the coarse fibres (Fig. 2). In the first phase of the study (MDFs coded from A to E), the resin content in the middle layer was reduced from 10.5 to $6.5 \mathrm{wt} \%$, but the $10.5 \mathrm{wt} \%$ resin was maintained in the surface layers. In the second phase (MDFs coded from $\mathrm{F}$ to I), the density of the MDF was gradually decreased from 730 to $650 \mathrm{~kg} / \mathrm{m}^{3}$. The contents of wood fibres and UF resin in the surface and middle layer were gradually decreased (Table 1). The shelling ratio (surface/middle layer) of all the MDFs was kept constant at 1:1. The amount of the UF resin in the surface layers was fixed at $10.5 \mathrm{wt} \%$ for all the MDFs. As a catalyst, aqueous ammonium chloride (at $1 \mathrm{wt} \%$ of solids content of resin) was incorporated into the UF resin.

The middle-layer fibres were put in the drum type blender (Altrad ${ }^{\mathrm{TM}}$; model: $250 \mathrm{~L}$ ). Then, the UF resin was applied by a nozzle spray gun on the wood fibres for $5 \mathrm{~min}$. The amounts of the UF resin used in the MDF panels were given in Table 1. This procedure was also applied for the surface fibres. The surface and middle layers were uniformly distributed in the forming box $(400 \mathrm{~mm}$ by $400 \mathrm{~mm}$ ) with a caul at the bottom. A wax paper was used on the caul to prevent bonding between the mat and cauls. Following the pre-pressing, the mats were put in the hydraulic hot press (Cemil Usta company, model: SSP 180). The mats were hot pressed at $3.5 \mathrm{~N} / \mathrm{mm}^{2}$ and $190{ }^{\circ} \mathrm{C}$ for $480 \mathrm{~s}$ to obtain MDFs having a density of $700 \mathrm{~kg} / \mathrm{m}^{3}$. The different densities of the MDFs were made by adjusting pressure. The maximum hot-press pressure was gradually decreased from 3.5 to $3.1 \mathrm{~N} / \mathrm{mm}^{2}$ to obtain different MDF densities ranging from 700 to $650 \mathrm{~kg} / \mathrm{m}^{3}$. Hot-press pressure for the MDFs having $730 \mathrm{~kg} / \mathrm{m}^{3}$ was increased to $3.6 \mathrm{~N} / \mathrm{mm}^{2}$. Three panels were produced from each type of MDF (Table 1). The final thickness of all the MDF panels was $10 \mathrm{~mm}$. The specimens were conditioned at standard atmospheric condition having $20{ }^{\circ} \mathrm{C}$ and $65 \%$ relative humidity.

\section{Determination of technological properties of MDF}

Twenty-four-hour thickness swelling (TS) of the MDF specimens was determined in accordance with EN 317 [5]. Fifteen MDF specimens were used in the swelling tests. The changes in the dimensional stability were carried out according to EN 318 [6]. The bending strength and bending modulus of the 12 specimens were determined in accordance with the requirements of EN 310

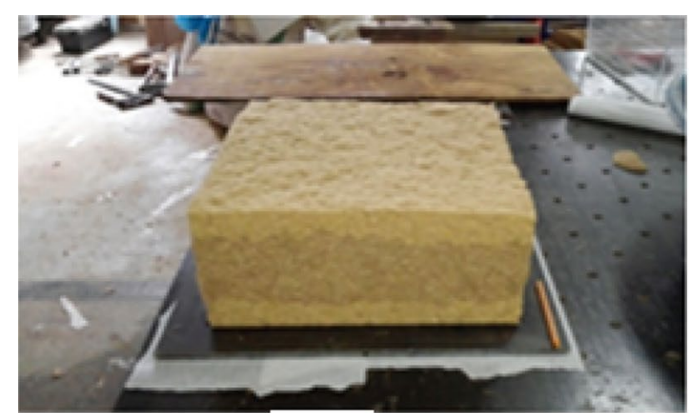

a

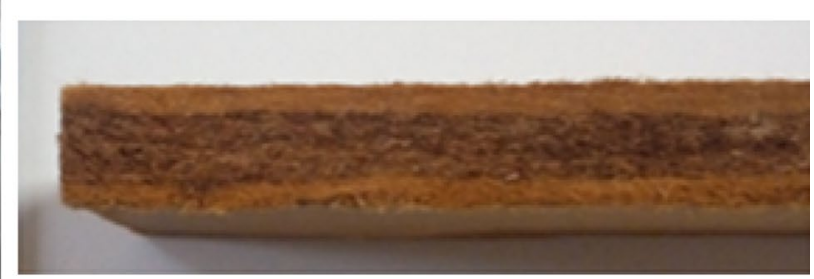

b

Fig. 2 a Three-layer MDF mat before hot pressing. b Cross section of three-layer MDF panel

Table 1 Experimental design

\begin{tabular}{llllll}
\hline MDF type & $\begin{array}{l}\text { Face layer ratio (\%) (fine } \\
\text { fibres of pine) }\end{array}$ & $\begin{array}{l}\text { Core layer ratio (\%) (coarse } \\
\text { fibres of beech) }\end{array}$ & $\begin{array}{l}\text { Resin content in face } \\
\text { layer (wt\%) }\end{array}$ & $\begin{array}{l}\text { Resin content in core } \\
\text { layer (wt\%) }\end{array}$ & $\begin{array}{l}\text { Target density } \\
\text { of } \mathbf{M D F}\left(\mathbf{k g} / \mathbf{m}^{\mathbf{3}}\right)\end{array}$ \\
\hline $\mathrm{A}$ & 50 & 50 & 10.5 & 10.5 & 700 \\
$\mathrm{~B}$ & 50 & 50 & 10.5 & 9.5 & 700 \\
$\mathrm{C}$ & 50 & 50 & 10.5 & 8.5 & 700 \\
$\mathrm{D}$ & 50 & 50 & 10.5 & 7.5 & 700 \\
$\mathrm{E}$ & 50 & 50 & 10.5 & 6.5 & 700 \\
$\mathrm{~F}$ & 50 & 50 & 10.5 & 10.5 & 730 \\
$\mathrm{G}$ & 50 & 50 & 10.5 & 10.5 & 700 \\
$\mathrm{H}$ & 50 & 50 & 10.5 & 10.5 & 675 \\
$\mathrm{I}$ & 50 & 50 & 10.5 & 10.5 & 650 \\
\hline
\end{tabular}


[7]. Internal bond strength of the ten specimens was carried out on the ten specimens in accordance with the requirements of EN 319 [8]. The density of the specimens was determined in accordance with EN 323 [9]. The tests results were statistically evaluated by analysis of variance (ANOVA, $p<0.05$ ). The MDF types showing statistically different means types were found using Duncan's multiple range analysis.

\section{Results and discussion}

\section{Physical properties of three-layer MDF}

The water resistance of the specimens was negatively influenced by the decreased UF resin content in the middle layer. The thickness swelling of the specimens increased from 34.2 to $49.2 \%$ when the amount of resin was reduced from 10.5 to $6.5 \%$ in the middle layer of the MDF. The significant differences between the MDF groups are presented in Table 2. According to EN 622-5 standard [10], the maximum thickness swelling for $10-\mathrm{mm}$-thick MDF panels used in dry conditions is $15 \%$. The thickness swelling values of the MDF panels were found to be higher than the maximum value specified in EN 622-5. This may be explained by the fact that no wax or other hydrophobic substance was used in the MDF manufacture.

The MDFs produced with UF resin contents of 10.5 and $9.5 \mathrm{wt} \%$ did not show significant differences in the physical properties. When the amount of resin is increased in the middle layer, the surface of the fibres is more covered with resin. In addition, the resin fills the micro-voids in the middle layer, which slows down the penetration of the water into the middle layer of MDF. Wood-based composites absorb most of water through their edge when they are exposed to the water [11].

The linear expansion (from 65 to $85 \%$ relative humidity) and linear contraction (from 65 to $35 \%$ relative humidity) of the specimens were increased by the decreased resin content. For example, as the relative humidity in the conditioning room decreased from 65 to $30 \%$, the linear contraction of the specimens raised from 0.15 to $0.33 \%$ with decreasing resin content in the middle layer (10.5 to $6.5 \%)$. Based on the results of the measurement, the linear expansion and thickness swelling increased with decreasing resin content in the middle layer (Table 2). Some significant differences were observed in the linear contraction and expansion values (Table 2).

The results showed that the amount of UF resin in the middle layer can be reduced from 10.5 to $9.5 \mathrm{wt} \%$ without significant changes in the thickness swelling and dimensional stability of MDF specimens (Table 1). American National Standards Institute (ANSI) A.208.2 [12] standard was followed for comparing linear expansion, since all known European Norms or standards did not possess an maximum linear expansion for MDFs. Since there was no maximum requirement in the EN 318 standard, the results were compared with ANSI.A.208.2 standard. Maximum linear expansion of fibreboards performing between 50 and $80 \%$ relative humidity specified in ANSI A.208.2 standard is $0.33 \%$. The linear expansion values of the MDF specimens were lower than the maximum value (0.33\%) of ANSI A.208.2 standard.

Thickness swelling of the MDF specimens decreased with decreasing MDF density. However, no significant difference in the thickness swelling was found as the MDF density was decreased from 730 to $675 \mathrm{~kg} / \mathrm{m}^{3}$. However,

Table 2 Some physical properties of three-layer MDF panels

\begin{tabular}{|c|c|c|c|c|c|c|c|}
\hline \multirow{3}{*}{$\begin{array}{l}\text { MDF code (wt } \% \text { of resin } \\
\text { of core)/target density: } \\
\mathrm{kg} / \mathrm{m}^{3} \text { ) }\end{array}$} & \multirow[t]{3}{*}{ Density $\left(\mathrm{kg} / \mathrm{m}^{3}\right)$} & \multirow{3}{*}{$\begin{array}{l}\text { Equilibrium } \\
\text { moisture } \\
\text { content (\%) }\end{array}$} & \multirow{3}{*}{$\begin{array}{l}\text { Thickness } \\
\text { swelling ( } 24 \mathrm{~h}) \\
(\%)\end{array}$} & \multicolumn{4}{|c|}{ Dimensional changes in with relative humidity at $20^{\circ} \mathrm{C}$} \\
\hline & & & & \multicolumn{2}{|c|}{$\begin{array}{l}\text { Relative humidity ( } 65 \\
\text { to } 30 \% \text { at } 20^{\circ} \mathrm{C} \text { ) }\end{array}$} & \multicolumn{2}{|c|}{$\begin{array}{l}\text { Relative humidity ( } 65 \\
\text { to } 85 \% \text { at } 20^{\circ} \mathrm{C} \text { ) }\end{array}$} \\
\hline & & & & $\mathrm{LC}_{65 \text { to } 30}(\%)$ & $\mathrm{TSh}_{65 \text { to } 30}(\%)$ & $\mathrm{LE}_{65 \text { to } 85}(\%)$ & $\mathrm{TS}_{65 \text { to } 85}(\%)$ \\
\hline$A(10.5) /(700)$ & $696(21) a$ & $7.61(0.95) a$ & 34.2 (1.8)ae & $0.15(0.01) a f$ & $2.36(0.2) \mathrm{ad}$ & 0.14 (0.02)ae & $2.25(0.2) \mathrm{a}$ \\
\hline$B(9.5) /(700)$ & 698 (17)a & $7.60(0.84) a$ & $36.7(2.4) a b$ & 0.18 (0.03)ae & $2.85(0.2) a b$ & $0.17(0.03) a b$ & $2.54(0.3) a b$ \\
\hline$C(8.5) /(700)$ & 695 (13)a & $7.63(0.75) a$ & 40.8 (3.0)bc & 0.22 (0.02)be & $3.15(0.4) b$ & $0.19(0.02) b$ & $3.01(0.4) b$ \\
\hline$D(7.5) /(700)$ & 697 (20)a & $7.61(0.86) a$ & $43.4(2.7) \mathrm{cd}$ & $0.27(0.03) c$ & $3.94(0.3) c$ & $0.25(0.03) c$ & $3.78(0.2) c$ \\
\hline$E(6.5) /(700)$ & 700 (24)a & $7.62(0.90) a$ & $49.2(3.2) d$ & $0.33(0.04) d$ & $4.36(0.5) c$ & $0.30(0.04) d$ & $4.20(0.3) d$ \\
\hline$F(10.5) /(730)$ & 728 (26)b & 7.62 (0.77)a & 37.8 (2.0)ab & $0.19(0.02) \mathrm{e}$ & $2.94(0.3) a b$ & 0.17 (0.01)ab & $2.90(0.4) a b$ \\
\hline G (10.5)/(700) & 696 (21)a & $7.60(0.84) a$ & 34.2 (1.8)ae & 0.15 (0.01)a & $2.36(0.2) \mathrm{ad}$ & 0.14 (0.02)ae & 2.25 (0.2)a \\
\hline$H(10.5) /(675)$ & $675(17) c$ & 7.61 (0.79)a & 32.7 (1.5)ae & $0.13(0.02) f$ & $2.11(0.1) d$ & $0.11(0.01) \mathrm{ef}$ & $2.01(0.2) \mathrm{e}$ \\
\hline I (10.5)/(650) & 651 (19)d & 7.63 (0.83)a & 31.4 (3.4)e & $0.12(0.01) f$ & $1.95(0.2) d$ & $0.09(0.02) f$ & $1.84(0.1) \mathrm{e}$ \\
\hline
\end{tabular}

LC linear contraction, TSh thickness shrinkage, LE linear expansion, TS thickness swelling

The values in the parentheses are standard deviations. Groups with same letters (from a to $f$ ) in each column indicate no significant statistical difference ( $p<0.05$ ) between the specimens in the group according to Duncan's multiply range test 
further decrement in the MDF density $\left(650 \mathrm{~kg} / \mathrm{m}^{3}\right)$ significantly decreased the thickness swelling. As the MDF panel contact to water, the wood fibres swell, which cause an increase in the thickness of the MDF. These results were in good consistent with previous studies [13-16]. For example, Ganev et al. [15] reported that the thickness swelling values of the MDF specimens increased from 3.8 to $4.3 \%$ as the MDF density was increased from 0.54 to $0.80 \mathrm{~g} / \mathrm{cm}^{3}$.

\section{Mechanical properties of three-layer MDFs}

The bending properties, modulus of elasticity and bending strength of the MDF specimens were negatively influenced by the reduced amount of the resin in the middle layer (Table 3$)$. The results of statistical analysis $(p<0.05)$ are presented in Table 3 . The mechanical properties of all the MDF specimens did not meet the minimum requirements of EN 622-5 standard [10]. The bending strength of the MDF specimens decreased from 17.25 to $14.31 \mathrm{~N} /$ $\mathrm{mm}^{2}$ as the amount of UF resin in the middle layer of the MDFs was reduced from 10.5 to $6.5 \mathrm{wt} \%$. A similar result was found in the bending modulus (Table 3). As expected, the bending strength of the MDF specimens decreased, but there was no significant difference in the bending strength $\left(17.25\right.$ to $\left.15.82 \mathrm{~N} / \mathrm{mm}^{2}\right)$ when the amount of the resin was reduced from 10.5 to $7.5 \mathrm{wt} \%$ in the middle layer. No significant difference was found in the bending modulus (2149.4 to $2012.0 \mathrm{~N} / \mathrm{mm}^{2}$ ) of the MDF specimens produced with 10.5 and $8.5 \mathrm{wt} \%$ UF resins. Based on these findings, it can be said that the resin can be saved at least $2 \mathrm{wt} \%$ without significant decrease in the modulus of rupture and modulus of elasticity. According to the results of this study, the cost-benefit analysis of the reduction in the resin content indicated that $20 \%$ reduction in the UF resin cost may be achieved as the resin content was decreased from 10.5 to $8.5 \mathrm{wt} \%$ in the MDF production.

The internal bond strength of the MDF specimens decreased with decreasing resin content in the middle layer. However, there was no significant difference in the internal bond strength as the amount of the resin decreased from 10.5 to $8.5 \mathrm{wt} \%$ (Table 3). The results showed that a certain amount of the UF resin in the middle layer can be reduced without compromising the bending strength and bending modulus of the MDFs. This is because surface layers receive more of bending stresses than middle layers [17-19].

Although the bending properties of the MDF specimens decreased with decreasing panel density, no significant decrease was found in the modulus of elasticity and bending strength of the MDFs having a density between 730 and $675 \mathrm{~kg} / \mathrm{m}^{3}$. However, further decrement in the MDF density $\left(650 \mathrm{~kg} / \mathrm{m}^{3}\right)$ significantly decreased the bending strength and modulus of elasticity (Table 3 ). The internal bond strength of the MDF specimens decreased with decreasing density of the MDF, while no significant difference was found in internal bond strength of MDF specimens of densities between 730 and $675 \mathrm{~kg} / \mathrm{m}^{3}$. However, further decrement in the MDF density $(650 \mathrm{~kg} /$ $\mathrm{m}^{3}$ ) significantly decreased the internal bond strength (Table 3). This can be explained by the fact the compression between the fibres is decreased by the decreased panel density. When a higher density mat is pressed, a greater degree of contact between the fibres during the consolidation enables more effective formation of bond lines, resulting in higher internal bond strength [20]. Density of wood-based composites significantly affects the mechanical properties [21, 22]. The results showed that the MDF density could be decreased from 730 to $675 \mathrm{~kg} / \mathrm{m}^{3}$ without significantly decreasing the bending properties and internal bond strength (Table 3 ). The

Table 3 Some mechanical properties of three-layer MDF panels

\begin{tabular}{|c|c|c|c|}
\hline $\begin{array}{l}\text { MDF code (wt\% of resin of core)/target } \\
\text { density: } \mathrm{kg} / \mathrm{m}^{3}\end{array}$ & Bending strength $\left(\mathrm{N} / \mathrm{mm}^{2}\right)$ & $\begin{array}{l}\text { Modulus of elasticity in bending (MOE) } \\
\left(\mathrm{N} / \mathrm{mm}^{2}\right)\end{array}$ & $\begin{array}{l}\text { Internal bond } \\
\text { strength }(\mathrm{N} / \\
\left.\mathrm{mm}^{2}\right)\end{array}$ \\
\hline$A(10.5) /(700)$ & 17.25 (1.09)a & 2149.4 (134.7)a & $0.56(0.06) \mathrm{a}$ \\
\hline$B(9.5) /(700)$ & $17.01(0.92) a$ & $2085.6(126.5) a b$ & $0.54(0.06) \mathrm{a}$ \\
\hline$C(8.5) /(700)$ & $16.62(1.02) a b$ & $2012.0(102.8) a b$ & $0.50(0.04) a b$ \\
\hline $\mathrm{D}(7.5) /(700)$ & $15.82(0.71) a b$ & $1882.8(116.1) b$ & $0.47(0.03) \mathrm{bc}$ \\
\hline$E(6.5) /(700)$ & $14.31(0.74) b$ & $1740.5(98.5) \mathrm{c}$ & $0.41(0.04) c$ \\
\hline$F(10.5) /(730)$ & $17.83(0.94) a$ & 2192.5 (130.5)a & $0.59(0.05) \mathrm{a}$ \\
\hline G (10.5)/(700) & 17.25 (1.09)a & $2149.4(134.7) a b$ & $0.56(0.06) a b$ \\
\hline$H(10.5) /(675)$ & $16.72(0.88) a b$ & $2078.8(105.9) a b$ & $0.52(0.04) a b$ \\
\hline I (10.5)/(650) & $15.51(0.92) b$ & $1937.2(97.0) b$ & $0.50(0.05) b$ \\
\hline
\end{tabular}

Groups with same letters (from a to $c$ ) in each column indicate that there is no statistical difference $(p<0.05)$ between the specimens according to Duncan's multiply range test 
contact area between the wood fibres is increased by increased density of the MDF, namely increasing hotpress pressure. Higher contact area between the fibres provides better adhesion between the fibres, which increase the internal bond strength of the $\operatorname{MDF}[23,24]$.

\section{Conclusions}

The strength properties of three-layered MDFs did not decrease significantly as the amount of UF resin in the middle layer is ranging between 10.5 and $8.5 \mathrm{wt} \%$. Similarly, the dimensional stability of the MDF was not significantly influenced by the decreased amount of the resin (10.5 to $9.5 \mathrm{wt} \%$ ). The amount of the resin in the middle layer of three-layered MDF, unlike in single-layer MDF, could be reduced without any significant decrease in the physical and mechanical properties. Bending and internal bond strength were undermined by the decreased density of the MDF. However, there was no significant difference in the strength values of MDFs having density between 730 and $675 \mathrm{~kg} / \mathrm{m}^{3}$. Although all of the physical and mechanical properties of the boards in this experiment did not met the requirements specified in EN 622-5 standard for indoor applications of MDF, these properties could be improved by decreasing fibre size and increasing resin content in the core layer. For three-layer MDF manufacture, three mat-forming heads, two for the surface layers and one for the middle layer, are needed for the mat preparation of three-layer MDF. Defibration process may need two systems for the production of fine and coarse fibres. However, the energy needs for defibrillation of coarse fibres will be lower than that of the fine fibres. Based on the results of the present study, the main advantages of three-layer MDF over the single-layer MDF are their lower resin content and density without seriously undermining physical and mechanical properties. These advantages can be considered for the payback period of an investment for three-layer MDF production.

\section{Abbreviations}

ANOVA: analysis of variance; ANSI: American National Standards Institute; E1: emission 1; EN: European Norm; EFTA: European Free Trade Association; MDF: medium-density fibreboard; UF: urea-formaldehyde.
}

\section{Acknowledgements}

This study was supported by the TUBITAK (Scientific and Technological Research Council of Turkey) under Contract No: 1140263.

\section{Authors' contributions}

NA and TA designed the experimental design. NA carried out the physical and mechanical tests of the MDF panels. TA and TA interpreted the test results. NA and TA wrote the paper together, and edited it through to the final version. Both the authors read and approved the final manuscript.

\section{Funding}

This study was funded supported by the TUBITAK (Scientific and Technological Research Council of Turkey) (Grant number: 1140263).

\section{Availability of data and materials}

The datasets used and/or analysed during the current study are available from the corresponding author on reasonable request.

\section{Competing interests}

The authors declare that they have no competing interests.

Received: 3 May 2019 Accepted: 23 August 2019

Published online: 18 September 2019

\section{References}

1. European Panel Federation (2018) Types of wood-based panels and their economic impact. https://europanels.org/the-wood-based-panel-indus try/types-of-wood-based-panels-economic-impact/. Accessed 24 Jan 2019

2. Michanickl A (2004) Light wood based panels-state of the art trend. In: 4th European wood-based panel symposium, European Panel Federation, Hannover, 15-17 September 2004

3. Akgül M, Güler C, Çöpür Y (2010) Certain physical and mechanical properties of medium density fibreboards manufactured from blends of corn (Zea mays indurata Sturt.) stalks and pine (Pinus nigra) wood. Turk J Agric Forest 34:197-206. https://doi.org/10.3906/tar-0902-26

4. Akbulut T, Ayrilmis N (2006) Effect of compression wood on surface roughness and surface absorption of medium density fibreboard. Silva Fennica 40:161-167. https://doi.org/10.14214/sf.358

5. EN 317 (1993) Particleboards and fibreboards-determination of swelling in thickness after immersion in water. European Committee for Standardization, Brussels

6. EN 318 (1993) Wood based panels. Determination of dimensional changes associated with changes in relative humidity. European Committee for Standardization, Brussels

7. EN 310 (1993) Determination of bending strength and modulus of elasticity. European Committee for Standardization, Brussels

8. EN 319 (1993) Particleboards and fibreboards. European Committee for Standardization, Brussels

9. EN 323 (1993) Determination of density. European Committee for Standardization, Brussels

10. EN 622-5 (2009) Fibreboards - specifications. Part 5: Requirements for dry process boards (MDF). European Committee for Standardization, Brussels

11. Niemz P (2010) Water absorption of wood and wood-based panelssignificant influencing factors. In: Thoemen $\mathrm{H}$, Irle M, Sernek M (eds) Wood-based panels: an introduction for specialists. Brunel University Press, London

12. American National Standard ANSI A208.2 (2002) Medium density fibreboard (MDF) for interior applications. Composite Panel Association, Gaithersburg

13. Ayrilmis N, Laufenberg TL, Winandy JE (2009) Dimensional stability and creep behavior of heat-treated exterior medium density fibreboard. Eur J Wood Prod 67:287-295. https://doi.org/10.1007/s00107-009-0311-7

14. Benthien JT, Ohlmeyer M (2017) Influence of face-to-core layer ratio and core layer resin content on the properties of density-decreased particleboards. Eur J Wood Prod 75:55-62. https://doi.org/10.1007/s0010 7-016-1059-5

15. Ganev S, Cloutier A, Beauregard R, Gendron G (2005) Linear expansion and thickness swell of MDF as a function of panel density and sorption state. Wood Fiber Sci 37(2):327-336

16. Gul W, Khan A, Shakoor A (2017) Impact of hot pressing temperature on medium density fibreboard (MDF) performance. Adv Mater Sci Eng, Article ID 4056360, 6 p. https://doi.org/10.1155/2017/4056360

17. Rofii MN, Yumigeta S, Suzuki S, Prayitno TA (2011) Mechanical properties of three-layered particleboards made from different wood species. In: The 3rd international symposium of indonesian wood research society, 3-4 November 2011, Jakarta, Indonesia, pp 152-161

18. Simon A, Hirsch M, Christian Z (2016) Hybrid cross-laminated timber plates with beech wood cross-layers. Constr Build Mater 124:1007-1018. https://doi.org/10.1016/j.conbuildmat.2016.08.051

19. Hayashi K, Ohmi M, Tominaga H, Fukuda K (2003) Effect of board density on bending properties and dimensional stabilities of MDF-reinforced 
corrugated particleboard. J Wood Sci 49:398-404. https://doi. org/10.1007/s10086-002-0501-y

20. Chen S, Du C, Wellwood R (2010) Effect of panel density on major properties of oriented strandboard. Wood Fiber Sci 42:177-184

21. Hague J, Robson D, Riepen M (1999) MDF process variables-an overview of their relative importance. In: Maloney TM (ed). Proceedings of the 33th international particleboard/composite material symposium Washington State University, Pullman, WA, 13-15 April 1999

22. Woodson GE (1977) Medium density fiberboard from mixed southern hardwoods. In: Maloney TM (ed). Proceedings of the 11th internaional particleboard symposium, Washington State University, Pullman, WA, March 1977
23. Suchsland O, Woodson GE (1991) Fibreboard manufacturing practices in the United States. Madison, Department of Agriculture Forest Service, Agriculture Handbook

24. Warmbier K, Wilczyński A, Danecki L (2013) Effects of density and resin content on mechanical properties of particleboards with the core layer made from willow Salix viminalis. Ann Warsaw Univ Life Sci SGGW For Wood Technol 84:284-287

\section{Publisher's Note}

Springer Nature remains neutral with regard to jurisdictional claims in published maps and institutional affiliations.

\section{Submit your manuscript to a SpringerOpen ${ }^{\odot}$ journal and benefit from:}

- Convenient online submission

- Rigorous peer review

- Open access: articles freely available online

- High visibility within the field

- Retaining the copyright to your article

Submit your next manuscript at $\boldsymbol{\nabla}$ springeropen.com 